E w a D y bow ska ORCID: 0000-0002-0454-772X Akademia Ignatianum w Krakowie

\title{
Socjalizacja w rodzinie i kultura konsumpcyjna
}

\section{Socialization in the Family and Consumer Culture}

\begin{abstract}
ABSTRAKT
Celem artykułu jest ukazanie procesów socjalizacyjnych we współczesnej rodzinie ze szczególnym uwzględnieniem kontekstów przestrzeni życia codziennego, jakim jest kultura konsumpcyina. Przedmiot analiz stanowi środowisko wychowawcze, jakim jest rodzina wraz z uwarunkowaniami socjalizacji zwiqzanymi z dominujacq we współczesnym świecie kulturq konsumpcyinq. Wobec tak zarysowanej problematyki cel ten zostanie zrealizowany poprzez krytycznq analizę opracowań dotyczacych przemian socjalizacyjnych ponowoczesnej rodziny i kultury konsumpcyinej. Analiza przeprowadzona w artykule koncentruje się wokół trzech zagadnień. Nakreślony został jeden z kontekstów socjalizacji w rodzinie, jakim jest kultura konsumpcyina. Następnie ukazano główne aspekty socjalizacji w rodzinie jako mechanizmu poznawania systemu znaczeń i wdrażania do uczestnictwa osoby w danym układzie społecznym. W wyniku przeprowadzonych analiz wyłoniono kilka wniosków. W nakreślonych kontekstach wskazano wyzwania, jakie staja przed procesem socjalizacji w rodzinie $w$ odniesieniu do kultury konsumpcyinej. Niewatpliwie socjalizacja konsumencka pozwala młodemu pokoleniu na odnalezienie się we współczesnym świecie. Ważne jest, aby socjalizacja nie tylko na tym się skupiała, ale także kształtowała umiejętność dokonywania codziennych wyborów.
\end{abstract}

StOWA KLUCZOWE socjalizacja, socjalizacja w rodzinie, kultura konsumpcyina, socjalizacja konsumencka, konsumpcjonizm

\section{KEYWORDS}

socialization, socialization in the family, consumer culture, consumer socialization, consumerism

SPI Vol. 22, 2019/2

ISSN 2450-5358

e-ISSN 2450-5366

DOI: 10.12775/SPI.2019.2.003

Nadesłano: 24.04.2019 Zaakceptowano: 21.05.2019

Artykuły i rozprawy 


\section{ABSTRACT}

The aim of the article is to show the socialization processes at work in the contemporary family, with a particular emphasis on one of the contexts of everyday life which is consumer culture. The subject of analyzes is the educational environment of the family, along with the circumstances of socialization in the context of the consumer culture which dominates in the contemporary world. In the face of this problem, this goal will be achieved through a critical analysis of studies on socialization in the postmodern family and consumer culture. The analysis carried out in the article focuses on three issues. One of the contexts of socialization in the family, which is consumer culture, is outlined. Next, the main aspects of socialization in the family as a mechanism knowing the system of meanings and the implementation to the participation of a person in a given social reality. The result of the analyzes carried out led to several conclusions. In such contexts, the challenges faced by the process of socialization in the family with regard to consumer culture are indicated. Undoubtedly, consumer socialization allows the younger generation to find themselves in the modern world. It is important that socialization also shapes the ability to make everyday choices.

\section{Wprowadzenie}

Wiek XXI na skutek przemian społeczno-kulturowych przyniósł doświadczenie płynnej rzeczywistości. Człowiek często znajduje się w sytuacji, kiedy żyje na granicy dwóch lub czasami więcej subświatów, nieustannie poszukując nowych, satysfakcjonujących doznań. Wielowymiarowość życia współczesnej rodziny generuje także wielość równoległych rzeczywistości, w których żyje. Intensywne tempo życia oraz pojawiająca się rodzinna i pozarodzinna wielozadaniowość członków rodziny zmienia życie rodziny. Często równoległe funkcjonowanie jednostki w przestrzeni realnej i wirtualnej zmienia procesy wychowawcze oraz socjalizacyjne wobec dzieci i młodzieży. Zasadniczo można powiedzieć, że w ostatnich dziesięcioleciach zadania i funkcje rodziny nie uległy znaczącym zmianom ${ }^{1}$. Nadal

1 Por. W. Wrzesień, Modyfikacje wzorów socjalizacyjnych w czasach natogowych konsumentów, „Ruch Prawniczy, Ekonomiczny i Socjologiczny” 2014, R. LXXVI, z. 3, s. 261-263. 
rodzina pozostaje często pierwszym i najdłużej oddziałującym na dziecko środowiskiem życia. Nieustannie opieka, wychowanie oraz socjalizacja pierwotna dokonuje się $\mathrm{w}$ rodzinie i takie są społeczne oczekiwania od rodziny. Jednak konteksty, w jakich konstytuują się przestrzenie życia rodzinnego ulegają dynamicznym zmianom, pojawiają się nowe wymiary, w jakich przebiega życie rodzinne oraz procesy wychowawczo-socjalizacyjne $\mathrm{w}$ rodzinie. Jednym $\mathrm{z}$ takich kontekstów jest kultura konsumpcyjna, która stała się nieodłącznym elementem życia człowieka w XXI wieku. W kontekście wychowania $\mathrm{w}$ rodzinie pozostaje też pytanie o socjalizację $\mathrm{w}$ rodzinie i jej adekwatność w stosunku do zmieniających się uwarunkowań społecznych ${ }^{2}$. Dzisiaj często konsumpcja wyznacza pozycję społeczną osoby i niejako uzależnia ludzi od przedmiotów i usług.

Celem artykułu jest przeanalizowanie wybranych elementów procesu socjalizacji w rodzinie $\mathrm{z}$ uwzględnieniem przestrzeni życia, jaką stanowi kultura konsumpcyjna.

\section{Kultura konsumpcyjna kontekstem socjalizacii w rodzinie}

Konsumpcjonizm jest współcześnie jednym $\mathrm{z}$ dominujących stylów życia, przejawiającym się nadmiernym nabywaniem i spożywaniem dóbr ${ }^{3}$. Kulturę konsumpcyjną charakteryzuje „syndrom konsumpcyjny" polegający na szybkości, nadmiarze i mnożeniu odrzutów ${ }^{4}$. Konsumpcjonizm oznacza, że konsumpcja znalazła się w centrum ludzkiego życia. $Z$ jednej strony stanowi ideologię, $w$ innym ujęciu jest sposobem życia ${ }^{5}$. Według Zygmunta Baumana wynika to $\mathrm{z}$ tego, że człowiek we współczesnym społeczeństwie podporządkowany jest głównie roli konsumenta. Taką bowiem rolę ma zasadniczo do odegrania człowiek w kulturze konsumpcyjnej'.

2 Por. J. Charchuła, Socjalizacja adolescentów w rodzinie - perspektywa socjologiczna, w: Wokót rodziny i dziecka - wybrane zagadnienia z teorii i praktyki, red. E. Dybowska, M. Prucnal-Wójcik, Kraków 2017, s. 185.

3 Por. F. Bylok, Konsumpcja, konsument $i$ spoteczeństwo konsumpcyjne we wspótczesnym świecie, Katowice 2013, s. 141.

4 Por. Z. Bauman, Konsumowanie życia, Kraków 2009, s. 95.

5 Por. F. Bylok, Konsumpcja, konsument i spoteczeństwo konsumpcyjne we wspótczesnym świecie, dz. cyt., s. 141.

6 Por. Z. Bauman, Globalizacja, przeł. E. Klekot, Warszawa 2000, s. 95. 
Konsumpcjonizm wywodzi się z kategorii ekonomicznych, gdzie oznacza proces wykorzystywania usług i dóbr w celu zaspokojenia potrzeb jednostki. Często współcześnie konsumpcja staje elementarną koniecznością życiową, która postrzegana jest jako proces analizowania potrzeb, postaw i zachowań. Kultura konsumpcyjna „zaleca” nie tylko zauważanie potrzeb, ale także poszukiwanie bodźców i impulsów, które pozwalają na powstawanie oraz rozwój potrzeb, na nieustanne poszukiwanie możliwości nieograniczonego ich rozwoju ${ }^{7}$. Jest to swoistego rodzaju sztuczne generowanie potrzeb, by kupować coś bez praktycznej potrzeby, a jednocześnie wyrażać swój indywidualizm oraz dążyć do samorealizacji za pomocą nabytych dóbr materialnych. Cechą współczesnego człowieka zanurzonego w konsumpcjonizmie jest elastyczność czyli podatność na szybkie i nagłe zmiany, kierowanie się zasadą otwartości na wszystkie opcje ${ }^{8}$. Otwartość, czasami bezkrytyczna, na wszystko co przynosi rzeczywistość powoduje, że dzisiaj często „w centrum społecznie pożądanych wartości uprzywilejowane miejsce znajdują samorealizacja, osiąganie indywidualnych celów i rozwój możliwości, szczęście osobiste, wolność wyboru wartości, tożsamości, pozycji społecznej, stylu życia, realizacja własnych praw i potrzeb"

Kultura konsumpcyjna jest coraz bardziej obecna jako rzeczywistość zewnętrzna w prywatnej przestrzeni życia rodzinnego ${ }^{10}$. W takiej realności dzieci uczą się bardziej nie przestrzegania reguł, ale maksymalizowania własnych korzyści ${ }^{11}$.

Wydarzenia kulturalne w sferze konsumpcji stają się sezonowe, wielozmysłowe, „obrandowane” i podawane w formie gotowej do

7 Por. W. Muszyński, Kobieta i mall. Próba analizy socjologicznej, w: Putapki (po)nowoczesności. Rodzina, pteć i role spoteczne w ogladzie socjologicznym, red. K. Piątek, A. Barabasz, Bielsko-Biała 2009, s. 121.

8 Por. Z. Bauman, Praca, konsumpcjonizm i nowi ubodzy, Kraków 2006, s. 61.

9 Por. M. Biedroń, Wptywa kultury indywidualizmu na relacji między rodzicami i dziećmi, w: Dziecko w zmieniajacej się przestrzeni życia. Obrazy dzieciństwa, red. J. Izdebska, J. Szymanowska, Białystok 2009, s. 247; E. Dybowska, Upbringing and Socialization of a Child in the Family in the Era of Consumer Culture, „Pedagogika Rodziny. Family Pedagogy” 2017, nr 7(4), s. 132.

10 Por. W. Wrzesień, Modyfikacje wzorów socjalizacyjnych w czasach natogowych konsumentów, dz. cyt., s. 262.

11 Por. W. Wrzesień, Zmiana pokoleń w czasach globalnej anomii, „Societas/ Communitas" 2017, nr 2(24), s. 45. 
użycia (instant). Kultura staje się wydarzeniowa. To nie chęć uczestniczenia w jakimś wydarzeniu ma znaczenie, ale marka i siła przyciągania jakiegoś wydarzenia czy imprezy ${ }^{12}$. W kulturze konsumpcyjnej bycie kimś staje się nierozerwalne $\mathrm{z}$ pożądaniem i posiadaniem produktów. Otaczająca człowieka przestrzeń nasycona jest towarami konsumpcyjnymi i reklamami tych towarów oraz mnogością oferowanych usług. W kulturze konsumpcyjnej socjalizowanie odbywa się poprzez przygotowanie do funkcjonowania $\mathrm{w}$ świecie marek i komunikowania się za ich pomocą ${ }^{13}$.

Kultura konsumpcyjna „wytwarzana” jest przez społeczeństwo konsumentów. Konsumenci, jak twierdzi Z. Bauman, to osoby, które od kołyski aż po grób trenowane są w konsumpcyjnej percepcji świata i swojego w nim modus operandi. Świat jest postrzegany jako wielki magazyn części zamiennych. Od człowieka nie oczekuje się, że zadowoli się tym co ma, albo tym kim jest. Znamienne w kulturze konsumpcyjnej jest wywieranie nieustającej presji, by być kimś innym niż się jest. Generowanie niezadowolenia $\mathrm{z}$ aktualnego stanu rzeczy wynika z potrzeby zmiany, posiadania czegoś nowego ${ }^{14}$.

\section{Socjalizacja w rodzinie z uwzględnieniem kontekstu kultury konsumpcyinej}

Socjalizacja to proces czy mechanizm w rozwoju osoby, który wyznacza typ społecznego uczestnictwa jednostki w danym układzie społecznym. Proces ten umożliwia jednostce społeczne zaistnienie i stawanie się istotą społeczną, która swoje życie i swoją tożsamość kreuje w danym układzie społecznym poprzez sekwencję następujących po sobie różnych typów uczestnictwa. Odnosi się do społecznej istoty rozwoju człowieka i zakłada uwewnętrznienie norm i zasad

12 Por. T. Szlendak, K. Olechnicki, Megaceremoniaty i subświaty. O potransformacyjnych przemianach uczestnictwa Polaków w kulturze, „Ruch Prawniczy, Ekonomiczny i Socjologiczny” 2014, R. LXXVI, z. 2, s. 293-308.

13 Por. R. Kossakowski, Uprzedmiotowione i „obrandowane”. Dzieci w kulturze towarów, „Teraźniejszość - Człowiek - Edukacja” 2011, nr 1(53), s. 25-28.

14 Por. Z. Bauman, Konsumowanie życia, dz. cyt., s. 108-111. 
regulujących oraz funkcjonujących $\mathrm{w}$ stosunkach międzyludzkich w rzeczywistości społecznej, w której życiu uczestniczy ${ }^{15}$.

Socjalizacja to zapoznanie się człowieka ze społecznie konstruowanymi systemami znaczeń, to nauka rozumienia i używania znaków (języka i symboli), to poznawanie sposobów interpretowania ludzkich zachowań. Socjalizacja to także nabywanie umiejętności społecznie akceptowanego zaspokajania potrzeb oraz poznawanie i przyswajanie określonego systemu wartości. W wyniku socjalizacji człowiek nabywa umiejętności posługiwania się przedmiotami niezbędnymi do funkcjonowania $\mathrm{w}$ ramach danej społeczności ${ }^{16}$. W tradycyjnym rozumieniu socjalizacja oznacza proces dziedziczenia stabilnej hierarchii wartości, w trakcie którego dziecko nabywa umiejętności umożliwiające mu prawidłowe funkcjonowanie w środowisku społecznym, w którym żyje ${ }^{17}$.

W szerokim rozumieniu socjalizacja rozumiana jest jako nabywanie przez dziecko (osobę) społecznej dojrzałości czy kompetencji społecznych. $Z$ perspektywy pedagogicznej zwykle socjalizacja jest postrzegana w węższym rozumieniu jako nabywanie przez jednostkę elementarnych form zachowania się społecznie pożądanego ${ }^{18}$. Proces socjalizacji to kształtowanie się osobowości społecznej jednostki, dziecka, młodego człowieka i wchodzenie w kulturę. W dzisiejszym świecie w dużej mierze jest to także wchodzenie w kulturę konsumpcyjną ${ }^{19}$.

Podejmując tematykę procesu socjalizacji w rodzinie, należy ją odnosić przede wszystkim do fazy socjalizacji pierwotnej, obejmującej okres dzieciństwa, które pełni dominującą rolę dla tego procesu. Rodzina stanowi podstawową agendę dla socjalizacji pierwotnej. Socjalizacja dokonuje się wtedy w stosunkowo wąskim gronie osób w rodzinie, poprzez bezpośrednie relacje. Dziecko zdobywa wiedzę mądrość życiową przede wszystkim od społeczności, w której żyje.

15 Por. J. Modrzewski, D. Sipińska, Socjalizacja, w: Encyklopedia pedagogiczna XXI wieku, t. 5 (R-St), Warszawa 2012, s. 803.

16 R. Kossakowski, Uprzedmiotowione i „obrandowane”. Dzieci w kulturze towarów, dz. cyt., s. 22.

17 J. Juszczyk-Rygałło, Socjalizacja dziecka, jako proces ksztattowania tożsamości, „Edukacja Elementarna w Teorii i Praktyce” 2016, t. 11, nr 4(42), s. 15.

18 Por. J. Modrzewski, D. Sipińska, Socjalizacja, dz. cyt., s. 804.

19 Tamże, s. 808. 
Poprzez naśladownictwo, identyfikację uczy się wzorów zachowań dzięki obserwacji społecznych zachowań w najbliższym otoczeniu ${ }^{20}$. Możliwość codziennego obserwowania wzorów czy norm zachowania innych osób z czasem może stać się zinternalizowanym sposobem działania samego dziecka ${ }^{21}$. W fazie socjalizacji pierwotnej w rodzinie istotną rolę odgrywają związki uczuciowo-emocjonalne. Zwykle są one bardzo silne, a dziecko naśladuje zachowania osób znaczących, jakimi są w tej fazie życia przede wszystkim rodzice. Proces socjalizacji zawsze dokonuje się w konkretnej czasoprzestrzeni i określonym kontekście kulturowym. Jednym z czynników standaryzujących współcześnie proces socjalizacji jest konsumpcja. Stanowi ona także mechanizm społecznej kontroli, który dokonuje swoistego stanu zsocjalizowania jednostki ${ }^{22}$.

Rodzina, rodzice i jej zwyczaje jako przestrzeń, w której przede wszystkim dokonuje się socjalizacja pierwotna, oddziałuje na dziecko na cztery sposoby. Po pierwsze, uwzględniając mechanizmy socjalizacji, rodzina modeluje zachowania dziecka, dostarcza wzorów zachowań. Po drugie, inspiracje do zachowań konsumenckich dziecko czerpie z dyskusji dotyczących wyborów konsumenckich, jakie toczą się $\mathrm{w}$ rodzinie. Trzeci kanał socjalizacji w rodzinie stanowią relacje z rodzeństwem, przede wszystkim kiedy młodsze rodzeństwo naśladuje starsze. Czwarty element pierwotnej socjalizacji konsumenckiej w rodzinie polega na tym, że dostarcza ona okazji do samodzielnej aktywności ekonomicznej ${ }^{23}$.

W ten sposób, świadomy lub niezamierzony, dziecko ulega procesom kultury konsumpcyjnej w rodzinie. W zakresie socjalizacji jest to często przyspieszona socjalizacja konsumencka. Polega ona na tym, że dzieci mają coraz większy wpływ na decyzje konsumenckie, jakie podejmowane są w przestrzeni życia rodzinnego. Rodzice coraz wcześniej delegują na dzieci większy zakres decyzji konsumenckich w kategoriach nieprzeznaczonych dla dzieci, lecz dla całej rodziny, zaś przy zakupach pewnych kategorii dzieci stają się doradcami

Por. J. Turowski, Socjologia. Mate struktury spoteczne, Lublin 1993, s. 41.

Por. J. Charchuła, Socjalizacja adolescentów w rodzinie - perspektywa socjologiczna, dz. cyt., s. 187.

Por. J. Modrzewski, D. Sipińska, Socjalizacja, dz. cyt., s. 810-811, 814.

Por. A. Kolodziejczyk, Trzy podejścia do wyjaśniania natury procesu socjalizacji konsumenckiej, „Psychologia Społeczna” 2012, t. 7, nr 3 (22), s. 276. 
dorosłych. Mimo że nie posiadają pełni czynności prawnych, dzieci są ważnymi konsumentami w kontekście życia rodzinnego. Stanowią dobry materiał na konsumenta, gdyż rosną i rozwijają się, a w związku z tym mają coraz większe potrzeby. Często w rodzinach występuje preferencja potrzeb dzieci, zakupy dla nich realizowane są w pierwszej kolejności ${ }^{24}$. Jak twierdzi Tomasz Szlendak, społeczna rola konsumenta stanowi współcześnie jedno z kryteriów traktowania dziecka jako osobę dorosłą. Bycie konsumentem to dokonywanie świadomego wyboru konsumenckiego ${ }^{25}$. Dlatego mówi się o przyspieszonej socjalizacji, gdyż postawy, nawyki charakterystyczne dla osoby dorosłej przejawiają się w zachowaniach dzieci.

Umiejętności konsumenckie dziecko nabywa w rodzinie na drodze naśladowania i modelowania, kiedy to śledzi rozmowy, decyzje, działania rodziców. $Z$ dzieci wyrastają dorośli, a socjalizacja konsumencka, jakiej podlegają w okresie dzieciństwa i wczesnej młodości ma niebagatelny wpływ na późniejsze zachowania konsumenckie ${ }^{26}$. Już kilkumiesięczne dziecko sadzane jest w supermarketowym wózku, skąd może swobodnie oglądać półki wypełnione towarem, umieszczone na wysokości jego oczu ${ }^{27}$.

Socjalizacja konsumencka $\mathrm{w}$ rodzinie może być bezpośrednia lub pośrednia. Bezpośrednia będzie wtedy, gdy dzieci uczestniczą wraz $\mathrm{z}$ rodzicami w zakupach, a rodzice podpowiadają, co i dlaczego kupić. Socjalizacja konsumencka pośrednia ma miejsce, gdy kształtowane są nawyki, np. poprzez regularne czytanie tych samych gazet, powtarzalne rytuały oglądania telewizji. $W$ środowisku rodzinnym rodzicie w ten sposób ukazują dzieciom wzorce zachowania. W dużej mierze to, czego dziecko doświadcza $\mathrm{w}$ procesie wychowania $\mathrm{w}$ rodzinie, również w zakresie zachowań konsumenckich, kształtuje jego

B. Frątczak-Rudnicka, Dzieci w roli konsumentów - przyspieszona socjalizacja konsumencka, w: Zmiana czy stagnacja? Spoteczeństwo polskie po czternastu latach transformacji, red. M. Marody, Warszawa 2004, s. 92.

Por. T. Szlendak, Komercjalizacja dziecinstwa. kilka uwag krytycznych o niewygodnych wychowania dzieci w kulturze konsumpcji, „Kultura i Edukacja” 2005, nr 2, s. 71.

B. Frątczak-Rudnicka, Dzieci w roli konsumentów-przyspieszona socjalizacja konsumencka, dz. cyt., s. 92.

27 Por. T. Szlendak, Komercjalizacja dzieciństwa. Kilka uwag krytycznych o niewygodnych wychowania dzieci w kulturze konsumpcji, dz. cyt., s. 23. 
późniejsze zachowania, także zachowania konsumenckie ${ }^{28}$. Dziecko uczy się zachowań konsumenckich w domu, bezpośrednio a także pośrednio przez styl życia, ukształtowane w rodzinie nawyki i gusty, sposób spędzania wolnego czasu. Modelami dla dziecka są rodzice, śledzi ono rozmowy i decyzje rodziców, inicjuje dyskusje ${ }^{29}$. Socjalizacja konsumencka w rodzinie dostarcza dziecku ram do interpretacji własnego doświadczenia i uczy konfrontacji znaczeń z wymaganiami otoczenia i kultury ${ }^{30}$.

Wyróżniane są trzy sposoby uczestnictwa dzieci w rynku konsumenckim. Pierwszy sposób to konsumpcja bezpośrednia. Ma miejsce wtedy, kiedy dzieci samodzielnie dokonują zakupów wykorzystując posiadane środki finansowe. Drugi sposób dziecięcej partycypacji w rynku konsumenckim to konsumpcja pośrednia, w której dzieci wpływają na zakupy rodziców. Trzeci sposób to konsumpcja przyszła, która ma na celu wczesne przywiązywanie dzieci do konkretnych marek produktów ${ }^{31}$.

Proces socjalizacji w rodzinie, zwłaszcza $\mathrm{w}$ pełnej indywidualizmu kulturze konsumpcyjnej, napotyka na trudności, jednak rodzina pozostaje środowiskiem życia o największym znaczeniu dla kształtu i efektywności socjalizacji ${ }^{32}$. Mimo że znaczenie rodziny jest coraz mniejsze, to pozostaje ona środowiskiem dominującym dla socjalizacji ${ }^{33}$. „Rodzina w trakcie wszystkich etapów swojego cyklu życia jest przestrzenią permanentnej socjalizacji” ${ }^{34}$ - przede wszystkim

Por. R. Kossakowski, Uprzedmiotowione i „obrandowane”. Dzieci w kulturze towarów, dz. cyt., s. 26.

B. Frątczak-Rudnicka, Dzieci w roli konsumentów-przyspieszona socjalizacja konsumencka, dz. cyt., s. 92-93.

Por. A. Kołodziejczyk, Trzy podejścia do wyjaśniania natury procesu socjalizacji konsumenckiej, dz. cyt., s. 276.

31 Por. B. Łaciak, Komercjalizacja dzieciństwa, w: Dziecko w zmieniającej się przestrzeni życia. Obrazy dzieciństwa, red. J. Izdebska, J. Szymanowska, Białystok 2009, s. 162.

32 Por. T. Szlendak, Socjologia rodziny. Ewolucja, historia, zróżnicowanie, Warszawa 2012, s. 213.

33 Por. J. Charchuła, Socjalizacja adolescentów w rodzinie - perspektywa socjologiczna, dz. cyt., s. 189; S. Kawula, Ksztatty rodziny wspótczesnej. Szkice familologiczne, Torun 2005, s. 89.

34 W. Wrzesień, Modyfikacje wzorów socjalizacyjnych w czasach natogowych konsumentów, dz. cyt., s. 264. 
(jak już wspomniano) socjalizacji pierwotnej, ale na przestrzeni całego życia także socjalizacji wtórnej.

\section{Wyzwania dla socjalizacji w rodzinie wobec kultury konsumpcyjnej}

Proces socjalizacji polega na kształtowaniu osobowości społecznej człowieka, zwłaszcza dziecka. Proces ten odbywa się w konkretnej przestrzeni społecznej, w konkretnym czasie historycznym. Ukazywanie norm i wartości zwykle miało miejsce w przekazie międzypokoleniowym, kiedy to młodsze pokolenie modelowało swoje zachowania na pokoleniu starszym. Współcześnie w społeczeństwie zdominowanym przez technologię, konsumpcję i globalizację wydaje się, że będzie chodziło także o jakiś inny wymiar socjalizacji. Za Margaret Mead można powiedzieć, że dziś częściej ma miejsce odwrócenie relacji międzypokoleniowych, bowiem dorośli uczą się pewnych zachowań od dorastającego pokolenia. Wyodrębnia ona w tym kontekście kulturę prefiguratywną (wcześniej miała miejsce kultura postfiguratywna i kultura konfiguratywna), która powoduje, że proces socjalizacji, nie tylko w rodzinie, odbywa się na drodze wdrażania dorosłych w zachowania znane młodszemu pokoleniu ${ }^{35}$. Przy zakupie sprzętów technologicznie zaawansowanych (komputery, telefony, sprzęt grający) dzieci występują zwykle w charakterze doradców rodziców, gdyż są lepiej zorientowane w ofercie i parametrach sprzętu ${ }^{36}$.

Współcześni rodzice muszą mieć świadomość, że dzieci uczą się rozumienia symboli i znaczeń otaczającego świata nie tylko od znaczących osób, ale także od producentów towarów i z mediów, a szczególnie z internetu. Mimo że rodzina pozostaje podstawową agendą socjalizacyjną, to jest nią także obecnie skomercjalizowany przekaz reklamowy oddziałujący nie tylko obok rodziny, ale wręcz jednocześnie $\mathrm{z}$ rodziną. Rodzic, sam kształtowany przez kulturę

35 Por. J. Modrzewski, D. Sipińska, Teoretyczne i praktyczne aspekty procesu socjalizacji, w: Dzieciństwo i mtodość. Standaryzacja socjalizacji inkluzyjnej. Przewodnik $i$ teksty do íwiczeń z socjologii wychowania, red. D. Sipińska, J. Modrzewski, A. Matysiak-Błaszczyk, Leszno 2010, s. 39; M. Mead, Kultura i tożsamość. Studium dystansu międzypokoleniowego, Warszawa 2000.

36 Por. B. Frątczak-Rudnicka, Dzieci w roli konsumentów - przyspieszona socjalizacja konsumencka, dz. cyt., s. 94. 
konsumpcyjną, konfrontowany jest nieustannie z jej skutkami. Stanowi to dla niego wyzwanie, by swoje dzieci „ocalić” od totalnego „mieć” na rzecz tego, aby też „być”. Wymaga to dużej czujności od rodzica, na przykład poprzez zwracanie uwagi na to, ile czasu dziecko spędza na nakłanianiu go do kupna czegoś, a ile na nakłanianiu do wspólnej zabawy. Znaczenia nabiera także słownictwo, jakim rodzicie zwracają się do dzieci. Już bowiem małe dzieci pytają o daną rzecz przez wypowiedzenie marki: pampers/pielucha; Samsung/telefon; Hotwheels/samochodzik; Barbie/lalka. W mentalności „mieć” kultury konsumpcyjnej dość szybko prezent staje się substytutem więzi rodzic-dziecko, rodzajem zadośćuczynienia za braku czasu. Może to powodować pogorszenie się relacji dziecka z rodzicami, gdyż aby kupować, mieć i posiadać stale nowe przedmioty, potrzebne są zasoby finansowe, a te trzeba zarobić czyli pójść do pracy, i to często nie tylko jednej ${ }^{37}$. Orientacja życia na „mieć” pozbawia człowieka wewnętrznej autonomii, skazuje go na ciągłą, wyniszczającą rywalizację, widzenie $\mathrm{w}$ drugim przede wszystkim konkurenta ${ }^{38}$.

Warto zachęcać rodziców, by w rodzinach kształtowali bardziej samodyscyplinę niż dyscyplinę. Może to wymagać zmiany sposobów myślenia o odpowiedzialności członków rodziny za siebie nawzajem. „Odpowiedzialność jednostki za pozostałych członków rodziny musi 'ograniczać' się do odpowiedzialności za decyzje i działania podejmowane przez nią samą, których rezultaty dotyczą całej rodziny" ${ }^{39}$. Uczenie i wdrażanie do samodzielności może prowadzić do błędów i porażek. Rodzice jednak nie mogą za wszelką cenę chronić potomstwa przed skutkami nierozsądnych poczynań. Czasami trzeba pozwolić dziecku na doświadczenie porażek i niepowodzeń, na stawianie czoła sytuacjom trudnym na miarę możliwości dziecka. Jeżeli przyjmuje się w dyskursie pedagogicznym, że rodzice kreują rzeczywistość życia rodzinnego i są odpowiedzialni za przygotowanie oraz

37 R. Kossakowski, Uprzedmiotowione i „obrandowane”. Dzieci w kulturze towarów, dz. cyt., s. 22-32.

38 A. Sebesta, Konsumpcjonizm i komercja jako wyzwanie pedagogiczne (refleksja nauczyciela etyki zawodowej), w: Wartości podstawowe w kontekstach wspótczesnych, red. M. Uliński, Kraków 2010, s. 295.

M. Biedroń, Wptywa kultury indywidualizmu na relacji między rodzicami i dziémi, w: Dziecko w zmieniajacej sie przestrzeni życia. Obrazy dzieciństwa, red. J. Izdebska, J. Szymanowska, Białystok 2009, s. 248. 
wprowadzanie osoby w życie społeczne, wyposażenie jej w niezbędne kompetencje społeczne oraz nauczenie sposobów osiągania sukcesu w społeczeństwie, to warto, aby poprzez zmienianie nawyków, wzorów zachowań kształtowali kreatywność i uczyli alternatyw dla posiadania marek i towarów. Mimo że kultura konsumpcyjna jest dominującą rzeczywistością $\mathrm{w}$ środowisku wychowawczym, to jednak socjalizacja młodego pokolenia ma przygotować osoby do podjęcia i wypełniania ról społecznych, co wiąże się z wchodzeniem w uregulowane życie społeczne oraz wzbogacaniem go swoją obecnością oraz działalnością ${ }^{40}$.

Nie ulega wątpliwości, że jednym z wielu wymiarów socjalizacji we współczesnym świecie jest socjalizacja konsumencka. W tym procesie dziecko zdobywa kompetencje (wiedzę, umiejętności, postawy) umożliwiające mu funkcjonowanie w roli konsumenta ${ }^{41}$. Pierwszych doświadczeń socjalizacyjnych dziecko doświadcza przede wszystkim w rodzinie, gdzie często rodzice są już zaawansowanymi konsumentami, charakteryzującymi się dużym indywidualizmem. Taka rzeczywistość nie sprzyja tworzeniu spójnej i stabilnej przestrzeni życia rodzinnego, nacechowanej niekonsekwencjami w podejmowanych decyzjach, niejednolitością socjalizacyjno-wychowawczego frontu, nadmiarem przywilejów, rezygnacją z precyzyjnego wytyczania granic, ufnością w negocjowalność. Dzieci chętnie to wykorzystują, realizując własne „wersje” socjalizacji ${ }^{42}$.

\section{Zakończenie}

Socjalizacja dzieje się świadomie bądź nieświadomie. „Człowiek przez całe życie, od narodzin aż do śmierci, pozostaje pod wpływem nigdy niekończącego się oddziaływania nań czynników

40 Por. A. Błasiak, Wychowanie w rodzinie, w: Pedagogika rodziny na poczatku XXI wieku w świetle pojęć i terminów, red. B. Sieradzka-Baziur, Kraków 2018, s. 148-149; A. Sebesta, Konsumpcjonizm i komercja jako wyzwanie pedagogiczne (refleksja nauczyciela etyki zawodowej), dz. cyt., s. 299.

41 Por. A. Kołodziejczyk, Trzy podejścia do wyjaśniania natury procesu socjalizacji konsumenckiej, dz. cyt., s. 272.

42 Por. W. Wrzesień, Modyfikacje wzorów socjalizacyjnych w czasach natogowych konsumentów, dz. cyt., s. 269. 
społecznych"33. W ten sposób uczy się internalizacji społecznej rzeczywistości Socjalizacja w rodzinie dotyczy przede wszystkim dziecka. Intensywne przemiany technologiczno-społeczno-kulturowe na przełomie XX i XXI wieku wyznaczają coraz to nowe płaszczyzny funkcjonowania człowieka. W związku z tym pojawiają się nowe wyzwania dla socjalizacji $\mathrm{w}$ tych zmieniających się warunkach. Jedną z takich płaszczyzn niewątpliwie jest kultura konsumpcyjna. W kulturze konsumpcyjnej dziecko staje się towarem, a towar trudno posądzać o podmiotowość. Aby socjalizacja w kulturze konsumpcyjnej nie zagubiła podmiotowości dziecka (osoby), warto w procesie socjalizacji w rodzinie uwzględniać przygotowanie do dokonywania wyborów pośród mnogości różnych ofert. Taka prowadzona socjalizacja jest w stanie ukształtować samodzielnie myślącego człowieka, który będzie potrafil podejmować autonomiczne decyzje ${ }^{44}$.

Można się zastanawiać, czy konsumpcjonizm jest narzucany osobom i rodzinom, czy też jest efektem wolnego wyboru. Konsumowanie sterowane jest potrzebami. Od świadomości pojawiania się potrzeb zależy to, czy jednostka wybiera czy przyjmuje to, co jest jej „narzucane”. Należy zaznaczyć, że kształtowanie potrzeb odbywa się również w procesie socjalizacji. Współcześnie, w odniesieniu do kultury konsumpcyjnej ludzie zadowalający się skończonym zbiorem dóbr i potrzeb, którym wystarcza jedynie to, co uważają za potrzebne i nie szukają nowych potrzeb (pożądań), stają się „wyrzutkami społeczeństwa" lub wadliwymi konsumentami ${ }^{45}$.

Opisując syndrom konsumpcyjny Z. Bauman stwierdza, że trwanie zostało zdegradowane przez przemijalność. Wzrosła wartość nowości ponad wartość trwałości. Zdecydowane skróciła się czas dzielący pragnienie od jego spełnienia. Rzeczy posiadane przetrwają dłużej niż ich pożądanie. Kultura konsumpcyjna kreuje społeczeństwo nadmiaru i zbędności. To w pewien sposób generuje płynność życiowego $\mathrm{układu}^{46}$. Zatem socjalizacja dzisiaj powinna być socjalizacją do umiejętności dokonywania wyborów, a także do umiejętności

J. Juszczyk-Rygałło, Socjalizacja dziecka, jako proces ksztattowania tożsamości, dz. cyt., s. 14 .

R. Kossakowski, Uprzedmiotowione i „obrandowane”. Dzieci w kulturze towarów, dz. cyt., s. 26.

45 Por. Z. Bauman, Konsumowanie życia, dz. cyt., s. 108.

46 Por. tamże, s. 94-95. 
odpowiedzi na pytanie o sprawy najważniejsze dla człowieka. Rozmontowany kompletny system normatywnych regulacji czyni obecnie jednostkę odpowiedzialną indywidualnie za coraz większe obszary życia. Socjalizacja do dokonywania wyborów staje się istotna, gdyż odpowiedzialność za wybory, za działania następujące po tych wyborach, a także następstwa tych działań spoczywają w pełni na indywidualnej osobie ${ }^{47}$.

Podlegająca dynamicznym zmianom rzeczywistość społeczna stawia przed środowiskami wychowawczymi (a takim jest rodzina) konieczność wszechstronnego podejścia do procesu socjalizacji. Świadomie podejmowana socjalizacja, zwłaszcza pierwotna dokonywana w rodzinie, powinna dawać gwarancję przygotowania młodego człowieka do radzenia sobie $\mathrm{z}$ wyzwaniami współczesnego świata ${ }^{48}$. Wiąże się z tym mechanizm kontroli społecznej, gdyż od powodzenia procesu socjalizacji zależy funkcjonowanie jednostki w społeczeństwie w sposób globalny, a także w jednostkowych relacjach interpersonalnych.

\section{Bibliografia}

Bauman Z., Globalizacja, przeł. E. Klekot, PIW, Warszawa 2000.

Bauman Z., Konsumowanie życia, Wydawnictwo Uniwersytetu Jagiellońskiego, Kraków 2009.

Bauman Z., Praca, konsumpcjonizm i nowi ubodzy, Wydawnictwo WAM, Kraków 2006.

Biedroń M., Wptyw kultury indywidualizmu na relacje między rodzicami i dziećmi, w: Dziecko w zmieniajacej się przestrzeni życia. Obrazy dzieciństwa, red. J. Izdebska, J. Szymanowska, Trans Humana, Białystok 2009, s. $245-264$.

Błasiak A., Wychowanie w rodzinie, w: Pedagogika rodziny na poczatku XXI wieku w świetle pojeć i terminów, red. B. Sieradzka-Baziur, Wydawnictwo Naukowe Akademii Ignatianum w Krakowie, Kraków 2018, s. 137-172.

Bylok F., Konsumpcja, konsument i spoteczensstwo konsumpcyjne we wspótczesnym świecie, „Śląsk”, Katowice 2013.

47 Por. tamże, s. 98.

48 Por. J. Juszczyk-Rygałło, Socjalizacja dziecka - czas bezpowrotnie utracony (?), „Pedagogika" 2017, t. 26, nr 2, s. 55. 
Charchuła J., Socjalizacja adolescentów w rodzinie - perspektywa socjologiczna, w: Wokót rodziny i dziecka - wybrane zagadnienia z teorii i praktyki, red. E. Dybowska, M. Prucnal-Wójcik, Akademia Ignatianum w Krakowie, Wydawnictwo WAM, Kraków 2017, s. 183-200.

Dybowska E., Upbringing and Socialization of a Child in the Family in the Era of Consumer Culture, „Pedagogika Rodziny. Family Pedagogy” 2017, nr 7(4), s. 131-141.

Frątczak-Rudnicka B., Dzieci w roli konsumentów - przyspieszona socjalizacja konsumencka, w: Zmiana czy stagnacja? Spoteczeństwo polskie po czternastu latach transformacji, red. M. Marody, Wydawnictwo Naukowe Scholar, Warszawa 2004, s. 88-99.

Juszczyk-Rygałło J., Socjalizacja dziecka - czas bezpowrotnie utracony (?), „Pedagogika”, 2017, t. 26, nr 2, s. 49-56.

Juszczyk-Rygałło J., Socjalizacja dziecka jako proces ksztattowania tożsamosci, „Edukacja Elementarna w Teorii i Praktyce” 2016, t. 11, nr 4(42), s. $13-25$.

Kawula S., Ksztatty rodziny wspótczesnej. Szkice familologiczne, Wydawnictwo Adam Marszałek, Torun 2005.

Kołodziejczyk A., Trzy podejścia do wyjaśniania natury procesu socjalizacji konsumenckiej, „Psychologia Społeczna” 2012, t. 7, nr 3 (22), s. 272-280.

Kossakowski R., Uprzedmiotowione i „obrandowane”. Dzieci w kulturze towarów, „Teraźniejszość - Człowiek - Edukacja” 2011, nr 1(53), s. 21-35.

Łaciak B., Komercjalizacja dzieciństwa, w: Dziecko w zmieniajacej sie przestrzeni życia. Obrazy dzieciństwa, red. J. Izdebska, J. Szymanowska, Trans Humana, Białystok 2009, s. 61-174.

Mead M., Kultura i tożsamośc. Studium dystansu międzypokoleniowego, przeł. J. Hołówka, Wydawnictwo Naukowe PWN, Warszawa 2000.

Modrzewski J., Sipińska D., Socjalizacja, w: Encyklopedia pedagogiczna XXI wieku, t. 5 (R-St), Żak, Warszawa 2012, s. 803-814.

Modrzewski J., Sipińska D., Teoretyczne i praktyczne aspekty procesu socjalizacji, w: Dziecinstwo i mtodość. Standaryzacja socjalizacji inkluzyjnej. Przerwodnik i teksty do íwiczeń z socjologii wychowania, red. D. Sipińska, J. Modrzewski, A. Matysiak-Błaszczyk, PWSZ im. Jana Amosa Komeńskiego w Lesznie, Leszno 2010, s. 26-48.

Muszyński W., Kobieta i mall. Próba analizy socjologicznej, w: Putapki (po) nowoczesności. Rodzina, pteć i role spoteczne w ogladzie socjologicznym, red. K. Piątek, A. Barabasz, Wydawnictwo ATH w Bielsku-Białej, Bielsko-Biała 2009, s. 117-138.

Sebesta A., Konsumpcjonizm i komercja jako wyzwanie pedagogiczne (refleksja nauczyciela etyki zawodowej), w: Wartości podstawowe w kontekstach wspótczesnych, red. M. Uliński, Aureus, Kraków 2010, s. 293-299.

Szlendak T., Komercjalizacja dzieciństwa. Kilka uwag krytycznych o niewygodnych wychowania dzieci w kulturze konsumpcji, „Kultura i Edukacja”2005, nr 2, s. 20-28. 
Szlendak T., Olechnicki K., Megaceremoniaty i subświaty. O potransformacyjnych przemianach uczestnictwa Polaków w kulturze, ,Ruch Prawniczy, Ekonomiczny i Socjologiczny" 2014, R. LXXVI, z. 2, s. 293-309.

Szlendak T., Socjologia rodziny. Ewolucja, historia, zróżnicowanie, Wydawnictwo Naukowe PWN, Warszawa 2012.

Turowski J., Socjologia. Mate struktury spoteczne, Towarzystwo Naukowe KUL, Lublin 1993.

Wrzesień W., Modyfikacje wzorów socjalizacyjnych w czasach natogowych konsumentóww, „Ruch Prawniczy, Ekonomiczny i Socjologiczny” 2014, R. LXXVI, z. 3, s. 261-281.

Wrzesień W., Zmiana pokolen w czasach globalnej anomii, „Societas/Communitas" 2017, nr 2(24), s. 37-52.

\section{ADRES DO KORESPONDENCJI}

Dr Ewa Dybowska

Akademia Ignatianum w Krakowie

Wydział Pedagogiczny

Instytut Nauk o Wychowaniu

e-mail: ewa.dybowska@ignatianum.edu.pl 